\title{
DIREITO À MORADIA: uma utopia para os catadores de resíduos sólidos na cidade de Fortaleza-Ceará
}

\author{
Isabel Freitas Carvalho ${ }^{7}$ \\ Ana Virgínia Moreira Gomes ${ }^{2}$ \\ \& Letícia Brena Maciel ${ }^{3}$
}

Palavras-Chave

Direito à moradia. Catadores de Resíduos. Dignidade da Pessoa Humana.

\section{SUMÁRIO}

1. Introdução; 2. Metodologia; 3. Direito à moradia, um teto é essencial para a dignidade do ser humano; 4 . 0 desafio da efetivação do direito à moradia para os catadores de resíduos em FortalezaCE; 5. Programas habitacionais em Fortaleza: inobservância do direito à moradia para os catadores de resíduos; 6. Conclusão; 7. Referências.

\section{Resumo}

$\mathrm{O}$ artigo tem por objetivo avaliar em que medida o direito à moradia digna tem efetividade entre um dos grupos mais vulneráveis da população: os catadores de resíduos, tomando como caso de estudo a cidade de Fortaleza - CE. A Constituição Federal instituiu como fundamental o direito à moradia que está ligado diretamente com o direito à vida e, consequentemente, com a digni-

Isabel Freitas de Carvalho - Doutoranda em Direito Constitucional na Universidade de Fortaleza (UNIFOR), Mestre em Direito Constitu cional na Universidade de Fortaleza (UNIFOR) e Professora do curso de graduação em direito da Universidade de Fortaleza (UNIFOR) em Fortaleza, Ceará, Brasil.

${ }^{2}$ Ana Virgínia Moreira Gomes - Pós-doutora na School of Industrial and Labor Relations Cornell Universaty, Doutora em Direito na Universidade de São Paulo e Professora da pós-graduação em direito e da graduação em direito na Universidade de Fortaleza (UNIFOR) em Fortaleza, Ceará, Brasil.

${ }^{3}$ Letícia Brena Maciel - Graduanda em Direito na Universidade de Fortaleza (UNIFOR) em Fortaleza, Ceará, Brasil. dade da pessoa humana. Moradia digna é muito mais que uma edificação de um espaço físico de abrigo, é uma construção devidamente integrada ao espaço urbano e aos serviços públicos para que os indivíduos que nela residem possam viver com dignidade. Nas entrevistas com os catadores, 43,75\% não possuem um lugar para morar, vivem em situação de rua, em uma condição de vulnerabilidade extrema, expostos à contaminação de doenças e sujeitos a situações de violência. A renda financeira obtida por esses trabalhadores é insuficiente para cobrir os gastos com uma moradia. Ao final, constatou-se que os catadores de resíduos entrevistados se encontram em péssimas condições de moradia ou não possuem um lugar para morar, não participam das políticas públicas disponíveis por não conseguirem atender os requisitos exigidos pelos programas habitacionais. É necessário haver uma mudança nos critérios de participação dos programas para amenizar ou diminuir o quantitativo de pessoas que vivem em situação de rua, garantindo-Ihes o mínimo de dignidade. Foram realizadas pesquisas bibliográfica, documental e empírica, de campo, de caráter quantitativo, por meio da aplicação de 32 questionários. 


\title{
RIGHT TO HOUSING: an utopia for wastepickers in the city of Fortaleza - Ceará
}

\author{
Isabel Freitas Carvalho \\ Ana Virgínia Moreira Gomes \\ \& Letícia Brena Maciel
}

\section{Keywords}

Right to housing. Waste pickers.

Dignity of human person.

\section{SUMÁRIO}

1. Introduction; 2. Methodology; 3. Right to housing, a roof is essential for human dignity; 4. The challenge of realizing the right to housing for waste pickers in Fortaleza-CE; 5. Housing programs in Fortaleza: non observance with the right to housing for waste pickers; 6 . Conclusion; 7. References.

\section{Abstract}

The purpose of this paper is to evaluate the extent to which the right to decent housing is effective among one of the most vulnerable groups: wastepickers, taking as case of study the city of Fortaleza

- CE. The Federal Constitution instituted as fundamental the right to housing that is directly linked with the right to life and, consequently, with the dignity of the human person. Decent housing is much more than the building of a sheltered physical space, it is a construction that is properly integrated with the urban space and public services so that the individuals who live in it can live with dignity. In the interviews with the wastepickers, $43.75 \%$ do not have a place to live, live in the street, in a condition of extreme vulnerability, exposed to contamination of diseases and subject to situations of violence. The financial income earned by these workers is insufficient to cover the costs of a housing. In the end, it was found that the wastepickers interviewed are in poor living conditions or do not have a place to live, and they do not participate in existing public policies because they are unable to meet the requirements required by housing programs. There is a need to change the criteria for participation in these programs to reduce or decrease the number of people living on the streets, guaranteeing them a minimum of dignity. The paper was developed through bibliographic, documentary and empirical, quantitative field, research, through the application of 32 questionnaires. 


\section{INTRODUÇÃO}

$\mathrm{O}$ artigo tem por objetivo avaliar em que medida o direito à moradia digna tem efetividade entre grupos mais vulneráveis da população. A pesquisa analisa se catadores de resíduos, na cidade de Fortaleza, Ceará, têm acesso aos programas habitacionais instituídos pelo governo, considerando que esses programas devem possibilitar a concretização do direito à moradia com condições mínimas para uma vida digna.

A Constituição Federal de 1988, no bojo de seus direitos fundamentais, contempla a moradia como direito basilar. Direito esse que tem uma conexão direta com as necessidades vitais do ser humano e que somente foi expresso no texto constitucional a partir do ano 2000. Ter um lugar para morar faz parte da sobrevivência do indivíduo.

O direito à moradia está ligado ao princípio constitucional da dignidade da pessoa humana. A pesquisa desenvolvida retrata uma situação de exclusão social e de pobreza em que vivem os catadores de resíduos que trabalham nas ruas da cidade de Fortaleza. Os dados coletados através de uma pesquisa empírica apontaram que, aproximadamente, $88 \%$ dos entrevistados moram nas ruas ou pagam aluguéis diários ou mensais, vivendo em condições de extrema vulnerabilidade e pobreza. Constatou-se que cerca de $47 \%$ do grupo auferem renda mensal mínima de $\mathrm{R} \$$ 420,00 (quatrocentos e vinte reais) e máxima de $\mathrm{R} \$ 800,00$ (oitocentos reais) não atingindo sequer o salário mínimo vigente no país em 2018 de R\$954,00 (novecentos e cinquenta e quatro reais). $O$ reflexo dessa renda na vida dos catadores de resíduos impossibilita-os o pleno acesso à moradia. Isso representa a inobservância do princípio da dignidade da pessoa humana e a distância que esse contexto social se encontra da efetividade desse direito.

Os dados da pesquisa indicam que os catadores não têm acesso ao mercado imobiliário privado e nem são contemplados pelas políticas públicas de habitação existentes no município de Fortaleza. Esse é o retrato da exclusão social e da pobreza que atinge uma parcela da sociedade brasileira. Existem políticas habitacionais, porém os entrevistados as desconhecem ou não conseguem se inserir nos critérios legais exigidos por essas políticas.

\section{METODOLOGIA}

No desenvolvimento deste estudo, foi realizada uma pesquisa empírica com catadores de resíduos não-associados, ou seja, aqueles que não integram associações ou cooperativas, e exercem suas atividades laborais individualmente ou em grupos nas ruas da cidade de Fortaleza, mais especificadamente, nas ruas que compõe a "Regional 2" e a "Regional Centro". A abordagem do estudo é de natureza qualitativa e quantitativa. Essa última aconteceu por meio da aplicação de 32 questionários durante os meses de novembro a dezembro de 2017. O tamanho da amostra se justifica, conforme Triola (2014, p. 235), considerando-se que para uma população com distribuição aleatória, se o tamanho amostral for maior que 30, as médias amostrais têm distribuição que pode ser aproximada por uma distribuição normal, sendo o quantitativo considerado válido. Foi realizada, também, pesquisa do tipo documental e bibliográfica.

Os dados analisados no presente artigo foram tabulados através do software para análise quantitativa, Statistical Package for the Social Sciences (SPSS versão 21) e apresentados na forma descritiva por meio de tabelas. 
A investigação foi submetida ao Comitê de Ética em Pesquisa em Seres Humanos (Coética) da Universidade de Fortaleza, tendo sido aprovada quanto aos preceitos que regem a pesquisa com seres humanos, em especial os que estão contidos na Resolução do Conselho Nacional de Saúde (CNS) $N^{\circ}$ 466/12, com o parecer de número: 2.383.258, versão: 3, CAAE: 78111517.8.0000.5052, título da pesquisa: Catadores de resíduos e a incidência de consumo de drogas: uma realidade nas ruas de Fortaleza/CE?, tendo como resultado final: "O Colegiado recomenda a Aprovação ao projeto de pesquisa visto atender, na íntegra, às determinações da Resolução CNS/MS 466/12 e diretrizes."

A pesquisa teve o financiamento da Universidade de Fortaleza por meio do Edital Programa de Apoio a Equipes de Pesquisa 30/2017 da Diretoria de Pesquisa, Desenvolvimento e Inovação (DPDI).

\section{DIREITO À MORADIA, UM TETO É ESSENCIAL PARA A DIGNIDADE DO SER HUMANO}

Em meados do século $X X$, a consolidação da industrialização gerou o êxodo rural e, consequentemente, um aumento das áreas urbanizadas, gerando um impasse em relação ao direito à moradia no Brasil. Em decorrência dessa migração das pessoas do campo para a cidade ficou evidente que as áreas urbanas não estavam preparadas para receber um grande contingente populacional, já que não existiam políticas habitacionais que efetivasse o direito à moradia.

O uso do termo moradia pode se confundir com outros como habitação, domicílio ou residência. Porém, o rigor da adoção de uma locução ou outra não tem relevância para efeitos práticos. Para Souza (2013, p.117), tanto o direito à moradia como o de habita- ção, conforme a finalidade da lei que os define ou o direito que os declara, têm como essencial a preservação do exercício do direito de ficar, de viver ou de morar.

Importante destacar o disposto no artigo 1.414 do Código Civil Brasileiro que define como um dos direitos reais o direito de habitação. Esse direito real concede ao seu titular a possibilidade de residir gratuita e temporariamente em um prédio, com sua família ou sozinho. O imóvel só se destina à ocupação direta do beneficiário, onde esse não pode locar. Farias (2018, p. 920) explica que o proprietário do imóvel reserva todos os direitos dominiais, exceto a possibilidade do exercício da moradia, pois essa é destinada em favor do beneficiário do titular do direito real de habitação.

Mesmo existindo esse direito real de habitação, o principal direito continua sendo o mesmo, que é a moradia. Sabe-se da necessidade do homem em possuir um lugar para morar, daí surge a identidade natural dos termos moradia e habitação, onde o ordenamento jurídico brasileiro não visa, exclusivamente, a que alguém apenas habite um local, mas que exerça, goze e usufrua do direito à moradia.

Para Sarlet (2014a, p. 603), o direito à moradia é fundamental e autônomo, de forte conteúdo existencial. Pode-se incluir o direito à moradia no rol dos direitos da personalidade, uma vez considerado esse um direito de subsistência, como expressão mínima do próprio direito à vida e em função de sua vinculação com a dignidade da pessoa humana (SARLET, 2014b, p. 280).

A dignidade humana é um atributo intrínseco à pessoa humana, sendo positivada como um valor supremo da ordem jurídica pela Constituição Federal, um dos alicerces 
do Estado Democrático de Direito e um dos fundamentos da República Federativa do Brasil (artigo $1^{\circ}$, inciso III CF/88). Nas palavras de Canuto (2010, p. 174, 241), a dignidade da pessoa humana, tida como princípio fundamental da Constituição Federal, é um supraprincípio, alçado a célula mater dos demais princípios. No mesmo sentido Sarlet $(2015$, p. 102) explica que a dignidade é um elemento integrante e irrenunciável da pessoa humana, é algo que se reconhece, respeita e protege, mas não que possa ser criado ou the possa ser retirado, já que existe em cada ser humano algo que lhe é inerente. A dignidade da pessoa humana, sendo a base de realização dos princípios fundamentais constante na Constituição Federal, fundamenta os direitos sociais que formam o piso mínimo para que se possa viver com dignidade.

Morar sempre foi algo essencial para o ser humano e para as consecuções de suas finalidades. Direito à moradia não significa direito a uma casa própria, mas como explica Silva (2007, p. 186) deve-se garantir a todos um teto onde se abrigue a família de modo permanente, segundo a própria etimologia do verbo 'morar', do latim morari, que significa 'demorar', 'ficar'.

O direito à moradia foi reconhecido internacionalmente pela primeira vez na Declaração Universal dos Direito Humanos em 1948. O artigo 25 aponta que todo ser humano tem direito a um padrão de vida capaz de assegurar a si e a sua família saúde e bem estar, inclusive alimentação, vestuário, habitação, cuidados médicos e os serviços sociais indispensáveis, bem como direito à segurança em caso de desemprego, doença, invalidez, viuvez, velhice ou outros casos de perda dos meios de subsistência fora de seu controle (ONU, on line). Esses e outros direitos viabilizam condições mínimas de dignidade.

O reconhecimento pela Declaração dos Direitos Humanos influenciou a elaboração de outros tratados e normas internacionais que passaram a incluir o direito à moradia no rol de direitos humanos, servindo também de paradigma para ordenamentos nacionais. Ambos os pactos internacionais de 1966 que dispõem de forma mais específica acerca dos direitos humanos garantidos pela Declaração reconhecem o direito à moradia.

O Pacto Internacional de Direitos Econômicos, Sociais e Culturais contribuiu para a afirmação dos direitos humanos, expandindo o catálogo dos direitos sociais reconhecidos pela Declaração Universal dos Direitos Humanos. Foi o primeiro tratado internacional a dispor sobre o direito à moradia de forma adjetivada. Conforme seu Artigo 11, Parágrafo $1^{\circ}$, onde "Estados Partes do presente Pacto reconhecem o direito de toda pessoa a um nível de vida adequando para si próprio e sua família, inclusive à alimentação, vestimenta e moradia adequadas, assim como a uma melhoria contínua de suas condições de vida". O Pacto Internacional dos Direitos Civis e Políticos previu a proteção ao direito à moradia quando dispôs sobre a inviolabilidade do domicílio4.

Em 1976, na cidade de Vancouver, realizou-se a Primeira Conferência das Nações Unidas sobre Povoamentos Humanos (Habitat I). Em 1996, em Istambul, realizou-se a Segunda Conferência das Nações Unidas sobre Povoamentos Humanos (Habitat II), da qual resultou a Declaração de Istambul sobre Assentamentos Humanos e Agenda Habitat que traz em seu conteúdo a definição

4 Importante informar que o Pacto Internacional dos Direitos Civis e Políticos e o Pacto Internacional de Direitos Econômicos, Sociais e Culturais somente foram ratificados e promulgados no Brasil em 1992. (Decreto n592/1992 e Decreto n591/1992, respectivamente). 
de moradia adequada. Em 2016, em Quito, ocorreu a Terceira Conferência das Nações Unidas sobre Moradia e Desenvolvimento Urbano Sustentável (Habitat III), sendo elaborada a Nova Agenda Urbana, documento que orienta a urbanização sustentável pelos próximos 20 anos.

Em setembro de 2015, na cidade de Nova York foi discutida e aprovada, por 193 Estados-membros, na Assembleia Geral das Organizações das Nações Unidas (ONU) um documento intitulado: "Transformando Nosso Mundo: a Agenda 2030 para o Desenvolvimento Sustentável". Um dos objetivos da supracitada Agenda é tornar as cidades e os assentamentos humanos inclusivos, seguros, resilientes e sustentáveis, além de garantir o acesso de todos à habitação segura, adequada e a preço acessível, aos serviços básicos, além de urbanizar as favelas.

No Brasil, o direito à moradia somente foi inserido na Constituição Federal, de forma expressa, com a Emenda Constitucional $\mathrm{n}^{\circ} 26$ em 2000, fazendo parte do artigo $6^{\mathrm{a}}$ que trata dos direitos sociais. Porém, outros dispositivos constitucionais fomentam o direito à moradia, tais como, o artigo $5^{\circ}$, incisos XXII e XXIII, e o artigo 170, incisos I e II, que dispõem sobre o direito de propriedade e sua função social. Outrossim, o artigo 23 que disciplina a competência comum a todos os entes da federação de promover programas de construção de moradia e de melhoria das habitações. Essa competência administrativa comum encontra-se ao lado das competências comuns para assegurar o direito à saúde e à educação. Cita-se ainda o artigo 182 que trata da política de desenvolvimento urbano que tem por objetivo ordenar o pleno desenvolvimento das funções sociais da cidade e garantir o bem-estar de seus habitantes. Os artigos devem ser inter- pretados de forma sistemática com os fundamentos e objetivos constitucionais que asseguraram a dignidade da pessoa humana, a diminuição das desigualdades e a erradicação da pobreza, determinando, pois, a implantação de programas habitacionais voltados para a população de baixa renda.

No Brasil, o acesso à moradia é um direito social. Direito social fundamental e prestacional, que reclama do Estado uma prestação concreta para que seus titulares possam exercê-lo. Conforme aponta Silva (2007b, p. 286), os direitos sociais são prestações proporcionadas pelo Estado, de forma direta ou indireta, que estão contempladas em normas constitucionais e que possibilitam melhores condições de vida aos mais fracos; isto é, direitos que tendem a realizar a igualização de situações sociais desiguais.

Assim, o Estado tem o dever de implementar esforços para a execução e efetivação adequada desses direitos sociais, incluindo o da moradia. Como observa Rocha (2004, p.72), o Estado somente é democrático em sua concepção, constitucionalização e atuação, quando respeita o princípio da dignidade da pessoa humana. $O$ indivíduo sem um lugar adequado para abrigar a si e sua família contra as diversas ameaças naturais ou não, sem um local para sua intimidade e privacidade, sem um espaço para viver com um mínimo de saúde e bem-estar, não tem sua dignidade assegurada. Monteiro (2015, p. 45) exalta que o reconhecimento de que o ser humano tem direito a uma moradia adequada representou uma evolução na afirmação desse direito. Independentemente de existir o termo 'adequada', a noção de dignidade já deveria assegurar a garantia de um padrão mínimo de qualidade.

Conforme o entendimento do Comitê dos Direitos Econômicos, Sociais e Culturais 
sobre a expressão, mencionada no artigo 11 do Pacto Internacional dos Direitos Econômicos, Sociais e Culturais, moradia adequada não deve ser interpretada de forma restritiva, pelo contrário, deve ser vista como o direito de viver em algum lugar em segurança, paz e dignidade. O termo 'adequada' engloba ter espaço, estrutura física, proteção, iluminação e ventilação adequadas, dentre outros recursos básicos - tudo isso a um custo razoável - assim explica a Relatoria Especial para Direito à Moradia Adequada da Organização das Nações Unidas. (ONU).

Deve-se entender que o direito à moradia adequada é composto por três elementos: liberdades, garantias e proteções. No que concerne às liberdades, as medidas que garantem a moradia adequada incluem a proteção contra a remoção forçada, a destruição arbitrária e a demolição da própria casa; o direito de ser livre de interferências na sua casa, à privacidade e à família; o direito de escolher a própria residência, de determinar onde viver e de ter liberdade de movimento. No que concerne às garantias, as medidas que garantem a moradia adequada incluem: segurança da posse; restituição da moradia, da terra e da propriedade; acesso igualitário e não discriminatório à moradia adequada; participação, em níveis internacional e comunitário, na tomada de decisões referentes à moradia. E, por fim, as proteções incluem a proteção contra a remoção forçada (BRASIL, 2013).

Moradia não deve ser vista apenas como a existência de um teto, mas como uma construção devidamente integrada ao espaço urbano e aos serviços públicos para que os indivíduos que nela residem possam viver com dignidade. A moradia deve ser adequada com total integração à cidade, além de que, como explica Canuto (2010, p. 228), a moradia será sempre mais adequada quando mais respeitar a diversidade cultural, os padrões habitacionais dos costumes, não se dissociando dos aspetos econômicos, sociais, culturais e ambientais.

Moradia adequada deve, também, estar vinculada à promoção do direito à cidade. Isso significa que a moradia adequada deve necessariamente estar associada a um local em que existam possibilidades reais para o morador e a comunidade em que habita acessarem os recursos públicos e as vantagens oferecidas pela cidade (MASTRODI, 2016b, p. 865). Deve possuir fornecimento de água, luz, esgoto, acesso ao transporte público local, proximidade de hospitais e/ou postos de saúde e escola. Outrossim, a promoção de moradias não pode se dar de modo estanque da produção do espaço urbano. Planejar a cidade e promover a habitação são políticas de inclusão social que devem se dar de modo integrado.

Acrescentando um critério para moradia digna, Martins (2018, p. 80) aponta que os vínculos sociais formados em torno do ato de morar, como as relações de amizade e familiaridade, autonomia, liberdade e intimidade na vida cotidiana, são fundamentais para a concretização do direito à moradia. Os laços sociais e familiares formados a partir de uma boa vizinhança contribuem para um bom desenvolvimento psicossocial do ser humano.

O direito à moradia, inserido no rol dos direitos sociais e tido como fundamental, é uma norma de eficácia plena, porém, os direitos sociais dependem da atuação do Estado que, por meio de políticas públicas, torna esses direitos efetivos. ${ }^{5}$ Mastrodi (2016,

Com base na teoria da eficácia dos direitos fundamentais, temse uma divisão entre normas de eficácia plena (ilimitada), eficácia contida e eficácia limitada (normas de princípio organizativo e normas de princípio programático). Essa última classificação impõese a necessidade de uma lei infraconstitucional para que a norma passe a produzir efeitos. 
p. 1471) explica que, mesmo que as normas de direitos sociais sejam de eficácia plena, por tratarem da promoção de direitos fundamentais, também são de eficácia limitada porque são dependentes da atuação do Estado por meio de políticas públicas. Percebe-se, nesse sentido, que a modificação no papel que deve ser exercido pelo Estado possui suma relevância para que seja possível identificar o dever do Administrador em implementar o direito à moradia.

Se eficácia jurídica é a capacidade da norma produzir efeitos no mundo jurídico, a efetividade ou a chamada eficácia social é a execução desse direito, ou seja, a produção de efeitos no mundo fático. Para isso, explica Mastrodi (2016, p. 1472) que não basta termos, na Constituição, a positivação do direito à moradia, faz-se necessário que o Estado, provedor desse direito, faça com que na realidade social se observe a adequação da moradia, que compreende a segurança da posse, a disponibilidade dos serviços, economicidade, habitabilidade, localização e adequação cultural.

A eficácia social do direito à moradia se torna dependente de políticas públicas adotadas pelo administrador público. Barcellos (2018, p. 190) também considera que na construção da eficácia de direitos fundamentais existe a necessidade de haver políticas públicas razoavelmente complexas para a realização desses direitos, que precisam se desenvolver ao longo do tempo, devendo ser conduzidas pelo Poder Executivo.

Dworkin (2002, p. 32) utiliza o termo política para estabelecer um objetivo a ser alcançado, em geral uma melhoria no aspecto econômico, político ou social da comunidade, sempre relacionado com uma meta ou finalidade coletiva. A concretização do direito à moradia depende de uma prestação positiva do Estado, o que se dá por meio das políticas públicas, exercidas através de programas específicos, considerando-se que os indivíduos são titulares de direitos fundamentais, cujo dever de concretização é do Estado.

No Brasil a prestação positiva do Estado no tocante ao direito à moradia acontece por meio dos programas habitacionais, sendo o Programa Minha Casa, Minha Vida (MCMV) o de maior abrangência. No município de Fortaleza além do MCMV, existe o Programa Locação Social (PSL) e o Programa MeIhorais Habitacionais e a Regulamentação Fundiária (Prefeitura de Fortaleza, 2018). Esses quatro programas serão analisados na seção 5 a partir do exame dos dados da pesquisa empírica, apresentado a seguir.

\section{O DESAFIO DA EFETIVAÇÃO DO DIREITO À MORADIA PARA OS CATADORES DE RESÍDUOS EM FORTALEZA-CE}

As condições sociais e econômicas vivenciadas pelos catadores de resíduos sólidos no Brasil indicam uma situação de extrema vulnerabilidade e precariedade. 6 Essas duas características, no entanto, não são inerentes a esse tipo de trabalho, mas sim geradas pela ausência e pouca efetividade das leis e das políticas públicas. A existência do trabalho do catador tal como se dá revela dois aspectos muito importantes do nível de desenvolvimento socioambiental no qual o país se encontra. Primeiro, o poder público e a sociedade não cumprem sua responsabilidade de coletar e reciclar os resíduos gerados pelas cidades.7 Segundo, diante ${ }^{6}$ Para uma análise das condições sociais e econômicas dos catadores de resíduos no Brasil, ver IPEA, 2013.

7 O IPEA estima que "90\% de todo o material reciclado no Brasil seja recuperado dos resíduos pelas mãos destes agentes - (IPEA, 2012, p. 9), isto é, pelas mãos dos catadores de resíduos, que separam, coletam e dão um destino adequado aos resíduos. 
dessa irresponsabilidade ambiental, há uma transferência dessa tarefa para grupos mais vulneráveis da sociedade que passam a realizá-la de modo informal e degradante para o próprio trabalhador.

Mesmo diante da importância do trabaIho dos catadores para o manejo dos resíduos no Brasil, a profissão da catação de resíduos somente foi reconhecida em 2002 na Classificação Brasileira de Ocupações, do Ministério do Trabalho e Emprego (MTE) e, em consequência, o trabalho passou a ser melhor identificado nas pesquisas do IBGE (Censo e Pesquisa Nacional por Amostragem de Domicílios - PNAD).8 A legislação ambiental criou importantes marcos de proteção, mas ainda com pouca efetividade no Brasil. Em 2010, a Lei nº 12.305 instituiu a Política Nacional de Resíduos Sólidos (PNRS), que adota a política de inclusão dos catadores no processo de gerenciamento dos resíduos sólidos através de suas associações ou cooperativas.

No Ceará, em 2016, seguindo as diretrizes da PNRS, se adotou a Política Estadual de Resíduos Sólidos do Ceará (PERS/CE), prevista na lei estadual $n^{\circ} 16.032$ de 20 de junho de 2016, que em seu artigo 65 prevê a "bolsa catador", espécie de pagamento ambiental urbano que consiste em incentivos financeiros periódicos do Estado destinados às cooperativas e associações de catadores. O marco comum tanto da política nacional, quanto

\footnotetext{
"5192-05 - Catador de material reciclável Catador de ferro-velho, Catador de papel e papelão, Catador de sucata, Catador de vasilhame, Enfardador de sucata (cooperativa) 5192-10 - Selecionador de material reciclável Separador de material reciclável, Separador de sucata, Triador de material reciclável, Triador de sucata". MTE, Classificação Brasileira de Ocupações. Disponível em: http://www. mtecbo.gov.br/cbosite/pages/pesquisas/BuscaPorTituloResultado.jsf. Acesso em 07nov. 2018. Conforme o MTE, o catador é responsável por "coletar material reciclável e reaproveitável, vender material coletado, selecionar material coletado, preparar o material para expediccão, realizar manutenção do ambiente e equipamentos de trabalho, divulgar o trabalho de reciclagem, administrar o trabalho e trabalhar com segurança".
}

da política estadual é o foco nas associações e cooperativas como meio de inclusão dos catadores. Os catadores de resíduos, no entanto, exercem sua atividade organizados coletivamente, em associações ou cooperativas ou de forma autônoma nas ruas. ${ }^{9}$ Apesar de não existirem números precisos, pode-se estimar a existência no Brasil de 387.910 catadores de resíduos (IPEA, 2013). Em Fortaleza, esse número alcança 5.367 catadores, sendo que desses 2.232 trabalham de forma individual nas ruas da cidade (PERS).

O trabalho exercido nas ruas de forma autônoma, individualmente ou em pequenos grupos (por vezes, familiar), sem o aporte de uma associação ou cooperativa, alijado das políticas de inclusão, é marcado por condições de extrema insalubridade, periculosidade e penosidade. Exercendo um tipo de trabalho considerado em condições inaceitáveis (OIT, 2015), ${ }^{10}$ OS catadores na rua experimentam uma situação de exclusão e invisibilidade semelhante à vivenciada por pessoas em situação de rua. A vida na rua e sua invisibilidade em relação às políticas necessárias para manter condições básicas de dignidade são os elementos comuns que unem esses dois grupos. Esse vínculo comum é traduzido na definição de pessoa em situação de rua pela Política Nacional para População em Situação de Rua - PNPSR, instituída pelo Decreto $n^{\circ} 7.053$ de 23 de dezembro de 2009:

\footnotetext{
9 É interessante observar que há catadores que trabalham em grupos de três, quatro pessoas, nas ruas. Nesse caso, o trabalho mesmo organizado coletivamente se dá nas ruas.

10 O trabalho na catação de resíduos no Brasil se enquadra de forma precisa no conceito desenvolvido pela OIT de formas inaceitáveis de trabalho (FIT). Conforme a OIT, as FIT direcionam a ação da OIT para as situações que exigem uma intervenção prioritária, acelerando dessa forma a transição de grupos em situação de especial vulnerabilidade para uma situação de trabalho decente (GOMES; BERTOLIN, 2016, p. 391-408).
} 
População em situação de rua o grupo populacional heterogêneo que possui em comum a pobreza extrema, os vínculos familiares interrompidos ou fragilizados e a inexistência de moradia convencional regular, e que utiliza os logradouros públicos e as áreas degradadas como espaço de moradia e de sustento, de forma temporária ou permanente, bem como as unidades de acolhimento para pernoite temporário ou como moradia provisória. (Artigo $1^{\circ}$, Parágrafo Único, da PNPSR).

Os catadores de resíduos que trabalham nas ruas podem, portanto, ser caracterizados como pessoas em situação de rua que utilizam essas como espaço de moradia, lar e sustento de forma temporária ou permanente. Enquanto alguns catadores utilizam a rua como moradia, outros pernoitam no trabalho (nas ruas) por dias seguidos.11 Um dos objetivos da PNPSR é o de "assegurar o acesso amplo, simplificado e seguro aos serviços e programas que integram as políticas públicas de saúde, educação, previdência, assistência social, moradia, segurança, cultura, esporte, lazer, trabalho e renda" (Artigo $7^{\circ}$, Inciso I, da Política Nacional para População em Situação de Rua).

A moradia constitui, portanto, um dos objetivos da PNPSR, integrada a outros objetivos, inclusive de promoção do trabalho e renda. No caso dos catadores de resíduos, essa visão transversal é essencial. Primeiro, porque como observam Gomes, Dias e López (2019,

Em pesquisa sobre os catadores de resíduos no centro de Fortaleza realizada em 2006, Rabelo, Silva e Carneiro (apud SILVA, 2017) observam que "a maioria dos catadores pertencentes ao Centro de Fortaleza-CE trabalha no período diurno, porém alguns também trabalham à noite e têm o hábito de dormir no seu local de trabalho (nas ruas)". p. 23), as pessoas em situação de rua Vivem o -duplo processo de exclusão: do trabalho formal e do direito à moradia previsto na Constituição Federal de 1988. Uma exclusão é consequência da outra: a situação de rua o exclui do mercado formal; a não inserção no mercado formal, leva-o a viver na rua". Segundo, porque a possibilidade de transição para um trabalho em condições decentes depende que suas condições de vida não levem a uma deterioração da pessoa e de sua dignidade.

O direito à moradia está intrinsecamente ligado com a dignidade da pessoa humana, como já ressaltado. Para que essa dignidade se torne uma realidade é necessário que se tenha garantia de que esse e outros direitos sejam observados, efetivados e usufruídos pelos indivíduos, mas essa certeza inexiste para os catadores de resíduos na cidade de Fortaleza.

Diante da pesquisa de campo realizada com esses catadores, optou-se por analisar, além da categoria que trata da moradia, outras constantes no questionário aplicado junto ao grupo, quais sejam: sexo, estado civil, situação residencial (moradia), grau de escolaridade, jornada de trabalho e renda auferida com o trabalho de catador. Dos 32 entrevistados na pesquisa, somaram 72,3\% do sexo masculino e $27,7 \%$ do sexo feminino. No tocante ao estado civil, 56,2\% eram solteiros, $6,2 \%$ casados, 3,2\% divorciados e $34,3 \%$ tido como outros, dentre esses últimos os que se encontravam em união estável, conforme a Tabela 1. 
Tabela 1: Estado civil e sexo dos catadores de resíduos

Tabulações cruzadas

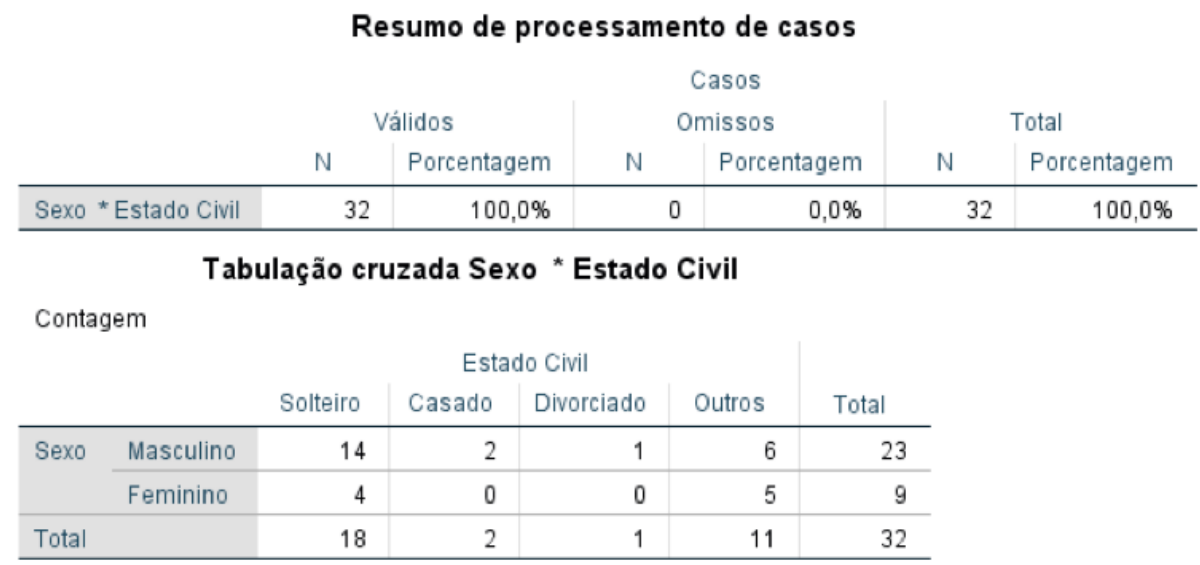

Tanto no caso de trabalhadores que vivem sozinhos, quanto aqueles que vivem com sua família, há necessidade de uma moradia adequada, ou seja, aquela que envolva a construção de um espaço físico que permita ao ser humano usufruir de seus direitos e necessidades básicas (MONTEIRO, 2015 , p.110). A moradia tem que acatar às necessidades físicas de proteção e abrigo contra o clima e os perigos da rua, tem que atender aos anseios psicológicos, criando espaço pessoal e individual, bem como um espaço coletivo para atender os anseios da família e dos amigos.

Observou-se com a pesquisa que grande parte dos catadores de resíduos entrevistados não usufrui do direito à moradia. Ter um lugar para morar onde é possível repousar, alimentar-se, higienizar-se, conviver com sua família, ter privacidade, não é a realidade desses indivíduos. Sem um teto é difícil exercer direitos básicos. Dos 32 (trinta e dois) entrevistados, 14 (quatorze), o que corresponde a $43,75 \%$, vivem na rua e, no mesmo quantitativo $43,75 \%$, vivem em locais alugados, como mostra a Tabela 2.

\section{Tabela 2: Situação residencial dos catadores de resíduos}

Tabulações cruzadas

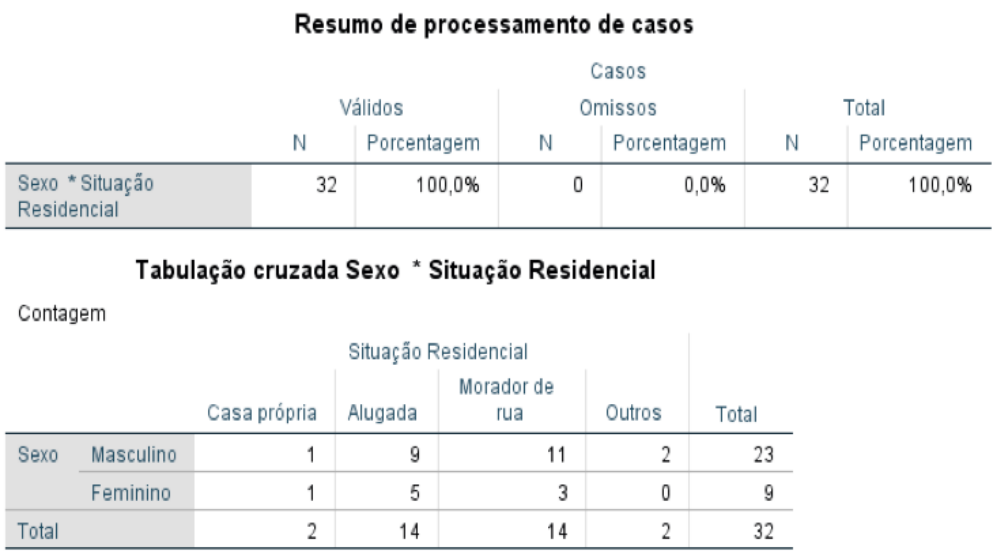


Em algumas entrevistas, foi possível ouvir relatos de que, parte do lucro, do dinheiro recebido no dia com a venda do material reciclável, seria para pagar um lugar para dormir, pernoitar. Por diversas vezes, esse lugar é no próprio depósito do comprador dos resíduos coletados - o intermediário ou deposeiro. Parte dos entrevistados possuía um lugar para morar, porém, como essa moradia se encontrava distante do local onde desempenhavam seu trabalho como catador de resíduos, acabavam pernoitando na rua. Alegaram que, financeiramente, era mais vantajoso ficar na rua durante os dias em que exerciam a catação.

Os demais entrevistados afirmaram que não tinham um lugar para morar e que, quando conseguiam dinheiro com a venda do material reciclado dormiam em alguma 'pousada', lugar onde banhavam-se e descansavam.
Contatou-se que quase a metade dos catadores de resíduos entrevistados se encontra em situação de rua, sem uma moradia, um lugar para abrigar-se, numa condição de vulnerabilidade extrema, expostos a contrair contaminações, doenças e sujeitos a qualquer situação de violência que a rua oferece. $O$ direito à moradia constitucionalmente previsto não chega até essas pessoas. A jornada de trabaIho diária, de $78,1 \%$ dos entrevistados, varia de 6 a 15 horas, conforme Tabela 3. Ao menos $50 \%$ desses trabalhadores têm uma jornada de trabalho que ultrapassa às 8 horas diárias garantida pelo inciso XIII, do Artigo $7^{\circ}$ da Constituição Federal (direito fundamental dos trabalhadores), ${ }^{12}$ muitas vezes, sem descanso para a alimentação.

${ }^{12}$ Nesse sentido, esse achado no tocante à jornada de trabalho é reforçado por Silva (2017) em pesquisa com catadores nas ruas do Centro de Fortaleza: "a minoria (7\%) trabalha um turno (4 horas/dia), $19 \%$ trabalham dois turnos (8 horas/dia), 32\% trabalham três turnos (12 horas/dia), 16\% trabalham quatro turnos (16 horas/dia), 19\% trabalham acima de 16 horas/dia e $7 \%$ não soube informar".

\section{Tabela 3: Jornada diária de trabalho dos catadores de resíduos}

\begin{tabular}{|c|c|c|c|c|c|c|}
\hline \multicolumn{7}{|c|}{ Resumo de processamento de casos } \\
\hline & \multicolumn{6}{|c|}{ Casos } \\
\hline & \multicolumn{2}{|c|}{ Válidos } & \multicolumn{2}{|c|}{ Omissos } & \multicolumn{2}{|c|}{ Total } \\
\hline & $\mathrm{N}$ & Porcentagem & $\mathrm{N}$ & Porcentagem & $\mathrm{N}$ & Porcentagem \\
\hline $\begin{array}{l}\text { Sexo * Qual sua Jornada } \\
\text { diária? }\end{array}$ & 32 & $94,1 \%$ & 2 & $5,9 \%$ & 34 & $100,0 \%$ \\
\hline
\end{tabular}

Tabulação cruzada Sexo * Qual sua Jornada diária?

Contagem

Qual sua Jornada diária?

\begin{tabular}{l|r|r|r|r|r|r|r} 
& & 0 a 5 horas & 6 a 10 horas & 11 a 15 horas & A partir de 16 & Indefinido & Total \\
\hline \multirow{2}{*}{ Sexo } & Masculino & 0 & 11 & 8 & 2 & 2 & 23 \\
\cline { 2 - 9 } & Feminino & 1 & 1 & 5 & 1 & 1 & 9 \\
\hline \multirow{2}{*}{ Total } & 1 & 12 & 13 & 3 & 3 & 32 \\
\hline
\end{tabular}

m. 
Com a pesquisa, verificou-se que a renda financeira auferida pela maior parte dos entrevistados, em decorrência do seu trabalho como catador de resíduos, é insuficiente para que possuam e/ou mantenham uma mora- dia. Constatou-se que 65,6\% recebem uma renda diária de, no máximo, $\mathrm{R} \$ 40,00$ (quarenta reais) por dia, trabalhando 5 dias na semana, o que totaliza $\mathrm{R} \$ 200,00$ (duzentos reais) semanais, conforme evidenciado na Tabela 4.

\section{Tabela 4: Renda diária/semanal dos catadores de resíduos}

\section{Resumo de processamento de casos}

\begin{tabular}{|c|c|c|c|c|c|c|}
\hline & \multicolumn{6}{|c|}{ Casos } \\
\hline & \multicolumn{2}{|c|}{ Válidos } & \multicolumn{2}{|c|}{ Omissos } & \multicolumn{2}{|c|}{ Total } \\
\hline & $N$ & Porcentagem & $N$ & Porcentagem & $N$ & Porcentagem \\
\hline $\begin{array}{l}\text { Sexo * Qual a renda } \\
\text { diária/semanal? }\end{array}$ & 32 & $94,1 \%$ & 2 & $5,9 \%$ & 34 & $100,0 \%$ \\
\hline
\end{tabular}

\section{Tabulação cruzada Sexo * Qual a renda diária/semanal?}

Contagem

Qual a renda diária/semanal?

\begin{tabular}{|c|c|c|c|c|c|c|c|}
\hline & \multicolumn{6}{|c|}{ Qual a renua diana/semanal? } & \multirow[b]{2}{*}{ Total } \\
\hline & & 0 a $R \$ 20,00$ & 21 a R\$ 40,00 & 41 a R\$ 60,00 & $\begin{array}{c}\text { Acima de R\$ } \\
61,00\end{array}$ & Indefinido & \\
\hline \multirow[t]{2}{*}{ Sexo } & Masculino & 3 & 12 & 5 & 1 & 2 & 23 \\
\hline & Feminino & 3 & 3 & 2 & 0 & 1 & 9 \\
\hline Total & & 6 & 15 & 7 & 1 & 3 & 32 \\
\hline
\end{tabular}

Dos entrevistados, 65,62\% não auferem o valor do salário mínimo de $\mathrm{R} \$ 954,00$ reais por mês (relativo ao ano 2018). Na definição de Crespo (2002, p. 9), a pobreza é a falta do que é necessário para o bem-estar material, especialmente alimento, moradia, terra, a insuficiência de renda e outros ativos.

A renda auferida pelos catadores de resíduos constitui um obstáculo para possuir e/ou manter uma 'moradia adequada'. Maricato (2002, p. 136) aponta que a regulação entre salário e preço de moradia é uma questão social, política e econômica. O que o salário dos trabalhadores vai cobrir de suas necessidades vitais é um produto histórico, não sendo uma realidade do momento agora.
Assim, a renda no final do mês ou da semana desses trabalhadores deveria ser suficiente para cobrir os gastos com a moradia adequada. A não inclusão social e produtiva dos catadores, que vendem os resíduos coletados por um valor baixo aos deposeiros, decorre da posição extremamente desvantajosa que esses trabalhadores ocupam na indústria da reciclagem, apesar da essencialidade da atividade que realizam. Essa exclusão produtiva ou inclusão injusta (SEN, 2010) afeta o direito desses trabalhadores de participarem de políticas públicas de acesso à moradia.

O fator econômico é um dos requisitos que impossibilita esse grupo de se beneficiar dos Programas Habitacionais existentes, pois 
sem uma renda salarial é difícil o acesso a esses Programas (Minha Casa Minha Vida, Regulamentação Fundiária ou Locação Social), além de ser inviável arcar com os custos decorrentes de uma moradia.
Os dados indicam que $40,6 \%$ dos entrevistados possui o grau de escolaridade correspondente ao ensino fundamental incompleto; $25 \%$ não concluíram o ensino médio e 18,7\% nunca estudaram, de acordo com a Tabela 5.

\section{Tabela 5: Grau de escolaridade dos catadores de resíduos}

\section{Tabulaçöes cruzadas}

\begin{tabular}{|c|c|c|c|c|c|c|c|c|c|}
\hline \multicolumn{10}{|c|}{ Resumo de processamento de casos } \\
\hline & & \multicolumn{8}{|c|}{ Casos } \\
\hline & & \multicolumn{2}{|c|}{ Válidos } & \multicolumn{2}{|c|}{ Omissos } & \multicolumn{4}{|c|}{ Total } \\
\hline & & $\mathrm{N}$ & Porcentagem & $\mathrm{N}$ & Porcentagem & & $\mathrm{v}$ & Porcent: & \\
\hline \multicolumn{2}{|c|}{$\begin{array}{l}\text { Sexo * Grau de } \\
\text { Escolaridade }\end{array}$} & 32 & $100,0 \%$ & 0 & $0,0 \%$ & & 32 & \multicolumn{2}{|c|}{$100,0 \%$} \\
\hline \multicolumn{10}{|c|}{ Tabulação cruzada Sexo * Grau de Escolaridade } \\
\hline \multicolumn{10}{|c|}{ Contagem } \\
\hline & & \multicolumn{8}{|c|}{ Grau de Escolaridade } \\
\hline & & $\begin{array}{l}\text { Nunca } \\
\text { estudou }\end{array}$ & $\begin{array}{c}\text { Ensino } \\
\text { fundamental } \\
\text { incompleto }\end{array}$ & $\begin{array}{l}\text { Ensino } \\
\text { fundamental } \\
\text { completo }\end{array}$ & $\begin{array}{l}\text { Ensino méd } \\
\text { incomplet }\end{array}$ & & & $\begin{array}{l}\text { sino } \\
\text { dico } \\
\text { inpleto }\end{array}$ & Total \\
\hline \multirow[t]{2}{*}{ Sexo } & Masculino & 4 & 11 & & 2 & 4 & & 2 & 23 \\
\hline & Feminino & 2 & 2 & & 0 & 4 & & 1 & 9 \\
\hline Total & & 6 & 13 & & 2 & 8 & & 3 & 32 \\
\hline
\end{tabular}

O baixo nível educacional dificulta o acesso a informações acerca dos Programas Habitacionais desenvolvidos pelo governo. Alguns entrevistados apontaram que desconhecem tais Programas e, entre aqueles que tinham algum conhecimento, muitos nunca foram obter maiores informações nos órgãos públicos para averiguar se tinham ou não a possibilidade de se enquadrarem nos critérios de alguns do referidos Programas.

No caso dos entrevistados, um dos fatores da não inserção no mercado de trabalho formal é a baixa escolaridade. $\mathrm{Na}$ idade adulta, em razão da precariedade em que vivem, qualquer melhoria financeira é utilizada em necessidades básicas mais imediatas, como alimentação e saúde, deixando a educação em segundo plano. Diante desse cenário, observa-se o pouco acesso ao direito à educação.

Outro dado da pesquisa mostra que 31,2\% dos entrevistados nunca exerceram outra atividade laboral que não fosse a de catador de resíduo. As demais atividades exercidas, como demonstra a Tabela 6, são: zelador, ajudante de pedreiros e auxiliar de cozinha. Dos entrevistados, 40,6\% deles estão inseridos na categoria 'outros', essa categoria inclui profissões como: manicure, babá, entregador de mercadorias e vigia. Esse dado sugere que a informalidade se associa à precariedade das condições de vida, incluindo a precariedade da moradia. Sem um trabalho digno que Ihe forneça renda razoável, difícil será ter um lugar para morar. 
Tabela 6: Possuiu outra profissão anterior a de catador de resíduos

\begin{tabular}{|c|c|c|c|c|c|c|}
\hline \multicolumn{7}{|c|}{ Resumo de processamento de casos } \\
\hline & \multicolumn{6}{|c|}{ Casos } \\
\hline & \multicolumn{2}{|c|}{ Válidos } & \multicolumn{2}{|c|}{ Omissos } & \multicolumn{2}{|c|}{ Total } \\
\hline & $\mathrm{N}$ & Porcentagem & $N$ & Porcentagem & $N$ & Porcentagem \\
\hline $\begin{array}{l}\text { Sexo *Tem uma } \\
\text { profissão anterior a de } \\
\text { catador? }\end{array}$ & 32 & $94,1 \%$ & 2 & $5,9 \%$ & 34 & $100,0 \%$ \\
\hline
\end{tabular}

Tabulação cruzada Sexo * Tem uma profissão anterior a de catador? Contagem

\begin{tabular}{|c|c|c|c|c|c|c|c|}
\hline & & \multicolumn{5}{|c|}{ Tem uma profissão anterior a de catador? } & \multirow[b]{2}{*}{ Total } \\
\hline & & Não & Zelador & $\begin{array}{l}\text { Ajudante de } \\
\text { pedreiro }\end{array}$ & $\begin{array}{c}\text { Auxiliar de } \\
\text { cozinha }\end{array}$ & Outros & \\
\hline \multirow[t]{2}{*}{ Sexo } & Masculino & 4 & 2 & 4 & 2 & 11 & 23 \\
\hline & Feminino & 6 & 1 & 0 & 0 & 2 & 9 \\
\hline Total & & 10 & 3 & 4 & 2 & 13 & 32 \\
\hline
\end{tabular}

Fonte: Pesquisa realizada pelas autoras

Em síntese, o diagnóstico mostra que a insegurança na situação de não se ter uma moradia afeta a possibilidade de usufruir outros direitos básicos. Não possuir um endereço é um dos obstáculos para acessar alguns serviços públicos, como os atendimentos em hospitais e postos de saúde. É necessário que o Estado, através das políticas públicas, seja mais atuante no sentido de que os serviços públicos essenciais cheguem até essas pessoas em situação de vulnerabilidade.

\section{PROGRAMAS HABITACIONAIS EM FORTALEZA: INOBSERVÂNCIA DO DIREITO À MORADIA PARA OS CATADORES DE RESÍDUOS}

Os programas habitacionais vigentes no município de Fortaleza são: o Programa Minha Casa Minha Vida, (MCMV), o Programa Locação Social (PSL); o Programa Melhorais Habitacionais e a Regulamentação Fundiária.

A Regularização Fundiária promove a segurança patrimonial por meio da entrega do Termo de Concessão de Direito Real de Uso
(CDRU), conhecido como "papel da casa". O Poder Executivo Municipal trabalha para garantir a escritura definitiva das moradias às famílias que residem em habitacionais construídos pela Prefeitura ou, ainda, que tenham sido erguidos em regime de mutirão.

Regularização fundiária são ações de intervenções efetuadas pelo Poder Público nas áreas de exclusão urbana. Gazola (2008, p. 119) define que regularização fundiária é um conjunto de projetos e ações integradas que objetivam a promoção da regularização jurídica, urbanística, ambiental e social, objetivando a promoção do desenvolvimento humano e urbano, em assentamentos irregulares, de forma inclusiva e sustentável.

Referido programa está regulamentado pela lei federal $n^{\circ}$ 13.465/2017. Para participar do programa é necessário morar em área de ocupação, sem oposição, há pelo menos cinco anos; morar em área situada em Zona Especial de Interesse Social (ZEIS); apresentar declaração da Administração Pública (União, Estado, Município ou DF) em casos 
de áreas pertencentes a esses Entes Públicos; apresentar os documentos: identidade (RG), cadastro de pessoa física (CPF) e comprovante de residência. Ressalta-se que esse programa não atende ao público dos catadores que residem na rua, uma vez que é requisito essencial possuir uma moradia.

O Programa Melhorias Habitacionais tem por objetivo proporcionar condições mínimas de habitabilidade por meio da construção e reparos de banheiros e outras estruturas básicas do lar, além de promover o acesso e ampliar a rede de saneamento básico em áreas de risco, carentes e/ou ocupações consolidadas no município de Fortaleza (Fortaleza, 2018). Esse Programa beneficia famílias selecionadas pelos seguintes critérios: possuir a casa própria e renda familiar abaixo de três salários mínimos. E, como condição para inserir-se no programa é imprescindível a apresentação do documento de identidade (RG), do cadastro de pessoa física (CPF) e do comprovante de renda. Observa-se que referido programa não atende o público dos catadores que residem na rua, uma vez que é requisito essencial possuir casa própria.

O Programa Locação Social (PSL) consiste na garantia de um auxílio financeiro mensal (aluguel social) às famílias que se enquadrem em situações previstas na Lei Municipal $n^{\circ} 10.328 / 2015$ e que não dispõem de recursos financeiros para adquirir ou alugar uma moradia.

Para a admissão no Programa Locação Social, o art. $7^{\circ}$ da supracitada lei esclarece que deverá possuir cadastro próprio na Secretaria Municipal do Desenvolvimento Habitacional de Fortaleza ou na Secretaria Municipal da Segurança Cidadã de Fortaleza. Para as pessoas em situação de vulnerabilidade, deverá haver a comprovação da condição de baixa renda ou de vulnerabilidade social. Essa comprovação é concedida pela Prefeitura de Fortaleza por meio da Secretaria Municipal de Assistência Social (Centro de Referência Especializado para Pessoa em Situação de Rua - Centro POP).

O tempo de permanência da família no PLS é de dois anos, mediante reavaliação semestral que constate a continuidade da condição que justificou o ingresso do beneficiário. O valor, em 2019, do aluguel é de $\mathrm{R} \$ 420,00$ (quatrocentos e vinte reais). Esse benefício é concedido em prestações mensais mediante pagamento direto do valor ao beneficiário cadastrado e, o respectivo valor será utilizado para pagamento integral ou parcial do aluguel, conforme o caso. A lei dispõe que a titularidade para o pagamento do benefício será preferencialmente concedida à mulher responsável pela família.

Dentre outras causas legais, o benefício será suspenso quando for dada solução habitacional definitiva para a família ou quando a família deixar de atender, a qualquer tempo, aos critérios definidos na lei.

Os beneficiários do Programa Locação Social são pessoas em situação de moradia em condições subumanas, áreas de risco iminente ou que tenham sido atingidas por qualquer espécie de desastre natural; em situação de desalojamento temporário e que estejam cadastradas nos programas habitacionais ou em processo de reassentamento; mulheres em situação de violência doméstica e/ou sexual, idosos, pessoas com deficiência ou pessoas com enfermidades graves; famílias ou pessoas em situação de baixa renda ou em situação de vulnerabilidade social e que se encontrem em situação de rua. 
Esse programa, em certa medida, atende ao grupo estudado - os catadores de resíduos sólidos não associados que trabalham nas ruas -, já que, como ressaltado, $43,75 \%$ se encontram em situação de rua. Entretanto, a burocracia existente nos procedimentos perante a Administração Pública municipal e a necessidade de observância aos requisitos legais dificultam o acesso dos catadores ao Programa Locação Social.

Um dos critérios de inserção e permanência no Programa (art. $9^{\circ}, \mathrm{III}$, da lei municipal $\mathrm{n}^{\circ}$ 10.328/15) é que o beneficiário terá que arcar com as despesas de água, energia elétrica, condomínio e outras taxas ou tributos porventura incidentes sobre o imóvel, observado o estipulado no instrumento contratual, bem como promover eventuais reparos necessários para a manutenção do imóvel nas condições em que foi recebido. Isso, em alguns casos, impede a permanência do catador no imóvel, pois como visto a renda auferida pelo trabalhador é insuficiente para arcar com as despesas básicas de alimentação e ainda sobrar para a manutenção da moradia e os encargos dela decorrentes.

O Programa Minha Casa, Minha Vida (MCMV) é regulamentado pela Lei Federal $n^{\circ} 11.977 / 2009$. Referido programa objetiva promover habitação de interesse social para famílias de baixa renda, em situação de coabitação, vulnerabilidade social e vivendo em área de risco ou violência. O programa é implementado pelo Governo Federal e realizado em parceria com a Caixa Econômica Federal ou Banco do Brasil, Governo do Estado e Prefeitura Municipal.

Importante realçar o artigo $5^{\circ}$ da referida lei que define o que deve ser observado ao construir as moradias contempladas pelo programa: localização do terreno na malha urbana ou em área de expansão que aten- da aos requisitos estabelecidos pelo Poder Executivo Federal, observado o respectivo plano diretor, quando existente; adequação ambiental do projeto; infraestrutura básica que inclua vias de acesso, iluminação pública e solução de esgotamento sanitário e de drenagem de águas pluviais e que permita ligações domiciliares de abastecimento de água e energia elétrica e a existência ou compromisso do poder público local de instalação ou de ampliação dos equipamentos e serviços relacionados a educação, saúde, lazer e transporte público. Todos esses requisitos legais cumprem o definido como moradia adequada, contudo, vários desses critérios não são observados na execução do programa.

O Programa Minha Casa, Minha Vida ainda é considerado o maior programa de construção de casas populares do país, promovendo o aquecimento da construção civil de baixo custo, o aumento de empregos e a acessibilidade à moradia para uma parcela da população. Porém, esse programa ainda é objeto de críticas de variadas naturezas. Dentre as principais críticas, Monteiro (2015, p. 144-145) aponta quatro, quais sejam: localização inadequada das unidades habitacionais, geralmente situadas em zonas periféricas bastante afastadas e com pouca conexão com a malha urbana. O segundo problema é referente às falhas na tipologia e tecnologia empregadas, uma vez que as plantas adotadas são pouco adaptáveis à população mais carente, ou seja, o projeto arquitetônico desenvolvido não é direcionado à moradia de baixa renda. O terceiro problema apontado é a utilização de materiais inadequados ao público destinado dessas moradias, sobretudo para a redução de custos, não permitindo aos moradores uma flexibilidade de adaptação ao seu modo de 
vida. O quarto trata da dificuldade de alteração de planta do imóvel, onde constatam-se problemas e defeitos já no momento da entrega do imóvel.

A Prefeitura de Fortaleza, por meio da Secretaria Municipal do Desenvolvimento Habitacional (HABITAFOR), atua na faixa 1 do MCMV. A faixa 1 é voltada para a habitação de interesse social, que atende famílias de baixa renda, ou seja, com renda familiar de 0 a $\mathrm{R} \$ 1.800,00$. Vale ressaltar que em Fortaleza aos beneficiários do Programa Locação Social será assegurada prioridade na inscrição em outros programas habitacionais promovidos pela Secretaria Municipal do Desenvolvimento Habitacional de Fortaleza (HABITAFOR) como o Programa Minha Casa Minha Vida (PMCMV).

O Instituto Brasileiro de Geografia e Estatística aponta que, pelo último censo realizado em 2010, 84,36\% da população brasileira encontra-se nas áreas urbanas do país, porém não existem dados precisos em relação a população que se encontra em situação de rua. Conforme Gomes, Dias e López (2019, p. 35):

Os dados mais recentes sobre a população em situação de rua, no Brasil, são os dados do IPEA, de 2015, que estimou a existência de 101.854 pessoas em situação de rua (NATALINO, 2016). No Ceará, dados do Cemaris (2017), notificaram 2.535 pessoas em situação de rua. Dos 184 municípios do estado, 66 municípios registraram a presença desse segmento populacional. Já no âmbito do município de Fortaleza, dados do $1^{\circ}$ Censo e Pesquisa Municipal sobre População em Situação de Rua, realizado em novembro de 2014, demonstrou que 1.718 pessoas estavam em situação de rua em Fortaleza.
Como apontado, para a inserção no Programa Minha Casa Minha Vida e no Programa da Locação Social, é preciso seguir a regulamentação da lei do respectivo programa. É necessária ainda a realização de um cadastro no Órgão da Administração Pública Direta com a apresentação dos documentos originais e atualizados: RG e CPF do titular e do cônjuge/companheiro (a), comprovante de residência atual (para o PMVMV), comprovante de renda, NIS (Cadastro Único) e, para aqueles que vivem situação de rua a comprovação da situação de vulnerabilidade.

O diagnóstico realizado pela pesquisa aponta para alguns aspectos da não efetividade do direito à moradia em relação aos catadores de resíduos nas ruas. Um deles é a dificuldade que existe para que o grupo cumpra os requisitos legais dispostos pelos programas habitacionais, como comprovação de renda salarial ou da condição de baixa renda e da situação de vulnerabilidade social. Além da apresentação da documentação básica como RG e CPF. Para o catador, portar sempre consigo essa documentação é difícil, pois o trabalho na rua atrapalha a guarda e conservação. Isso piora quando eles não possuem uma moradia, pois não tem onde guardar seus pertences. Com a burocracia dos procedimentos referentes à expedição desses documentos básicos perante órgãos da Administração Pública, torna o processo complicado, dispendioso e moroso. Quando se trata de grupos em situação de extrema vulnerabilidade, a política habitacional deveria ter critérios desenhados de forma específica para facilitar a transição da rua para uma moradia adequada. No caso em estudo, a exigência da renda deveria ser dispensada e a certificação da vulnerabilidade passar a ser a norma. Ademais, a política deveria prever um apoio para que as famí- 
lias se mantivessem no imóvel, inclusive no tocante aos bens móveis que guarnecem a residência.

Outro aspecto é a dificuldade do acesso às demais políticas públicas que possibilitem o uso e garantia de outros direitos fundamentais como a saúde e a educação, direitos básicos que estão ligados a uma vida digna juntamente com uma moradia e que, juntos, garantem uma melhoria na qualidade de vida dessa categoria de indivíduos.

A pesquisa traçou um diagnóstico entre os diferentes direitos fundamentais e a exclusão a esses direitos. Com base nos dados coletados, a falta de segurança nos locais utilizados como moradia (a rua) gera uma instabilidade da permanência dessas pessoas e de suas famílias, dificultando o acesso a serviços básicos como saúde ${ }^{13}$ e educação; a dificuldade de acesso a órgãos públicos e de informação acerca das políticas públicas; o baixo acesso das crianças à escola e dos adultos a programas de qualificação profissional; a dificuldade de acompanhar e prestar assistência social às pessoas em situação de rua e aos catadores de resíduos, dentro das possibilidades fáticas da estrutura estatal.

Assim, Gazola (2008, p. 115) esclarece que os programas habitacionais podem viabilizar a moradia de forma gratuita ou onerosa. Porém, em quaisquer das formas, sem que haja uma política de subsídios, esse direito não poderá ser apropriado para o cidadão de baixa renda. Mesmo em casos de doações, a inadequação da execução das políticas públicas pode forçar o beneficiário a abrir mão de seu direito, quando não possuir renda capaz de arcar com os custos da legalidade e na manutenção da moradia.

A maior parte dos entrevistados tem difi${ }^{3}$ No que concerne ao direito à saúde, os dados coletados foram analisados por Dias; Cavalcante; Gomes (2019, p. 141-160). culdade em se enquadrar nos requisitos dispostos nas leis municipais e federais que regulam os Programas Habitacionais e, alguns até os desconhecem. Daí a necessidade de adequação dos programas já existentes para atender às pessoas inseridas nas camadas mais vulneráveis da população; bem como é imprescindível um aprimoramento do ordenamento jurídico no tocante às formas de aquisição e transferência de bens imóveis possíveis de se tornarem moradias. Um exemplo desse tipo de política é o de normas municipais que priorizam a inscrição de catadores de resíduos no Programa Minha Casa, Minha Vida (MARTINHAGO; GOMES; LUCENA, 2014).

É necessária, pois, a realização de uma reestruturação dos programas habitacionais para que, o grupo de pessoas que se encontram em situação de vulnerabilidade, obtenha um alcance maior dos benefícios sociais oferecidos, de forma reduzir as desigualdades e garantir a execução do princípio da dignidade da pessoa humana e do direito à moradia.

\section{CONCLUSÃO}

O presente artigo analisou dados empíricos sobre a situação da moradia dos catadores de resíduos sem vínculo associativo em Fortaleza, CE. A situação da moradia entre o grupo pesquisado é precária, porque a maioria deles vive em situação de rua tornando esse direito inatingível para esse grupo.

O direito à moradia é um direito social; tais direitos tidos como fundamentais pela Constituição Federal devem corrigir desigualdades existentes na sociedade, desigualdades essas que dificultam ou impossibilitam o exercício de direitos básicos de alguns grupos de pessoas. 
A escolha do grupo estudado se deu em razão de sua exclusão socioprodutiva. Esses trabalhadores enfrentam obstáculos para exercerem direitos sociais básicos, como o direito à moradia. A pesquisa indicou que, dentre os entrevistados, a maioria possui baixo nível de escolaridade (40,6\% possuíam o ensino fundamental incompleto, $40,6 \%$ possuem o ensino fundamental incompleto e $18,7 \%$ nunca frequentaram a escola); trabalham longas jornadas (78,12\%, possuem uma jornada diária de trabalho que varia de 6 a 15 horas), e auferem uma renda mensal inferior ao salário mínimo (65,62\% não atingem o valor do salário mínimo de R \$954,00 reais por mês).14

No tocante à categoria moradia, observou-se que 43,75\% dos pesquisados encontram-se em situação de rua em condições de extrema vulnerabilidade e pobreza, utilizando a rua como espaço de moradia de forma permanente ou transitória. Dos entrevistados, 43,75\% vivem em habitações alugadas variando entre aluguéis diários ou mensais.

Os direitos sociais têm nas políticas públicas o meio para sua efetivação, dado seu caráter primordialmente prestacional. Assim, as falhas na implantação e no desenvolvimento dessas políticas públicas por parte do Estado resultam em prejuízos na efetivação desses direitos. No que se refere aos programas habitacionais existentes para garantir a moradia, observou-se uma baixa adesão do grupo pesquisado devido aos critérios de participação e inserção exigidos pelos programas.

A efetividade do direito à moradia depende, dentre outras medidas, da mudança dos requisitos impostos nos programas habitacionais e do combate à pobreza, uma vez ${ }^{14}$ Esse é o valor do salário mínimo à época da realização da pesquisa, em 2018 que uma das maiores causas do problema habitacional está na falta de acesso à renda financeira. Esse achado é reforçado pelos dados da pesquisa que revelam as péssimas condições de moradia dos catadores de resíduos entrevistados e a informalidade e precariedade que marcam o seu trabalho, mesmo constituindo a base da indústria de reciclagem.

Assim, diante da situação de exclusão social em que vivem os catadores de resíduos que trabalham nas ruas de Fortaleza, o estudo aponta que eles não possuem acesso a uma moradia digna e não conseguem atender os requisitos exigidos pelos programas habitacionais para neles se inserirem. $O$ estudo propõe que, para grupos vulneráveis, a exigência da renda deveria ser dispensada; a certificação da vulnerabilidade deve passar a ser a norma; a política deve assegurar um apoio para que as famílias se mantenham no imóvel, inclusive no tocante aos bens móveis que guarnecem a residência. O estudo sugere ser, portanto, necessária a mudança nos critérios de participação desses programas para possibilitar a transição de pessoas que vivem em situação de rua para uma moradia adequada, garantindo- Ihes o mínimo de dignidade.

\section{REFERÊNCIAS}

Barcellos. Ana Paula de. (2018). Curso de direito constitucional. Rio de Janeiro: Forense.

Brasil. Decreto n 591, de 06 de julho de 1992. Atos Internacionais. Pacto Internacional sobre Direitos Econômicos, Sociais e Culturais. Promulgação. Recuperado em 01 de julho de 2018, http://www.planalto.gov.br/ ccivil_03/decreto/1990-1994/d0591.htm.

Brasil. Secretaria de Direitos Humanos da Presidência da República. Direito à moradia adequada. (2013). Brasília: Coordenação Geral de Educação em SDH/ 
PR, Direitos Humanos, Secretaria Nacional de Promoção e Defesa dos Direitos Humanos. Recuperado em 05 de julho de 2018, http://unesdoc.unesco.org/images/0022/002254/225430POR.pdf.

Canuto, Elza Maria Alves. (2010). O direito à moradia urbana. Editora Fórum: Belo Horizonte.

Crespo, A. P. A. Gurovitz, E. (2002). A pobreza como um fenômeno multidimensional. São Paulo. RAEeletrônica. jul/dez. 1 (2). Recuperado em 11abril, 2018, http://www.rae.com.br/eletronica/index.cfm?FuseAction=Artigo\&ID=1178\&Secao=PÚBLICA\&Volu$m e=1 \&$ Numero $=2 \&$ Ano $=2002$.

Dworkin, Ronald. (2002). Levando os direitos a sério. Tradução de Nelson Boeria. São Paulo: Martins Fontes. Farias, Cristiano Chaves \& Rosenvald, Cristiano. (2018) Curso de direito civil, vol 5. 14.ed. Salvador: Editora JusPodivm

Fortaleza. Secretaria de habitação - HABITAFOR. Recuperado em 25 setembro, 2018, de https://habitacao. fortaleza.ce.gov.br

Gazola, Patrícia Marques. (2008). Concretização do direito à moradia digna. Belo Horizonte: Editora Fórum. Gomes, Ana Virginia Moreira; Dias, Eduardo Rocha; Matias, Mariana López. (2019). Catadores de Resíduos e População em Situação de Rua: (in)visibilidades e cidadania nas ruas de Fortaleza. Lumen Iuris. Recuperado em 08 jan. 2020, http://nedts.unifor.br/\#.

Gomes, Ana Virgínia Moreira; Bertolin. Patrícia Tuma Martins (2016). Trabalhos verdes e precários: A política de inclusão do trabalho do catador de resíduos sólidos no Brasil. Direito e Sustentabilidade, Florianópolis: CONPEDI, v. 2, n² 2, p. 391-408, 2016. Recuperado em 08 jan. 2020, https://www.conpedi.org.br/publicacoes/ yoii48ho/dzog9f77/3hcA83L46h4XMSgC.pdf.

IBGE. Instituto Brasileiro de Geografia e Estatística. Recuperado em 01 de julho, 2018, https://brasilemsintese.ibge.gov.br/populacao/distribuicao-da-populacao-por-situacao-de-domicilio.html.

IPEA. Instituto de Pesquisa Econômica Aplicada. (2012). Diagnóstico sobre Catadores de Resíduos Sólidos. Relatório de Pesquisa. Brasília: IPEA.

IPEA. Instituto de Pesquisa Econômica Aplicada. (2013) Situação Social das Catadoras e dos Catadores de Material Reciclável e Reutilizável - Brasil. Brasília: IPEA.

Maricato, Ermínia. (2002). Brasil, Cidades. Alternativas para a crise urbana.2. ed. Petrópolis: Editora Vozes.
Martinhago, Makelly Wickert; Gomes, Andréa da Silva \& Lucena, Emerson Antônio Rocha Melo de. A reciclagem e os aspectos socioeconômicos dos catadores de resíduos sólidos do aterro sanitário de IIhéus, Bahia. (2014). Informe Gepec. Toledo, v. 18, n. 2, p. 3750, jul./dez.

Martins, Ester Gouvêa \& Mastrodi, Josué. Direito à moradia: entre a efetivação autônoma e a sujeição ao direito de propriedade. (2018). Revista de Direitos Fundamentais \& Democracia, v.23, n. 2, p. 75 - 103, maio/ ago. Recuperado em 27 de setembro, 2018, de http:// revistaeletronicardfd.unibrasil.com.br/index.php/rdfd/ article/view/760.

Mastrodi, Josué \& Conceição, Paula Gomes da. Da carga normativa do direito à moradia e sua eficácia social: análise a partir de estudo de caso da cidade de Campinas, SP. (2016). Revista de Direito da Cidade, v.08, n. 4, p. 1468 - 1494. Recuperado em 01 de julho, 2018, de http://www.e-publicacoes.uerj.br/index.php/ rdc/article/view/24711/19151.

Mastrodi, Josué \& Zacarra, Zuzana Maria Loureiro. O que é o objeto "moradia" do Programa Minha Casa Minha vida? (2016b). Revista de Direito da Cidade, v.08, n. 3, p. 859 -885. Recuperado em 01, agosto, 2018, de http://www.e-publicacoes.uerj.br/index.php/rdc/article/view/22506.

Monteiro, Victor de Andrade. (2015). Direito à moradia adequada. Rio de Janeiro: Lumen Juris.

Nalini, José Renato. (2011). Direitos que a cidade esqueceu. São Paulo: Revista dos Tribunais.

ONU. Declaração Universal dos Direitos do Homem. Recuperado em 01 de julho, 2018, de http://www.brasil. gov.br/cidadania-e-justica/2009/11/declaracao-universal-dos-direitos-humanos-garante-igualdade-social. ONU. Relatoria Especial para o Direito à Moradia Adequada.Recuperado em 21 de setembro, 2018, de https://unhabitat.org/the-right-to-adequate-housing-fact-sheet-no-21rev-1/.

Rocha, Cármen Lúcia Antunes. (2004). O direito à vida digna. Belo Horizonte: Editora Fórum.

Sarlet, Ingo Wolfgang. (2015). A eficácia dos direitos fundamentais. 12.ed. Porto Alegre: Livraria do Advogado Editora.

Sarlet, Ingo Wolfgang; Marinoni, Luiz Guilherme \& Mitidiero, Daniel. (2014a). Curso de direito constitucional. 3. ed. São Paulo: Revista dos Tribunais.

Sarlet, Ingo Wolfgang. Algumas notas sobre a eficácia e efetividade do direito à moradia como direito de defesa aos vinte anos da Constituição Federal de 1988. In: 
Fernandes, Edésio \& Alfonsin, Betânia (Coord.). Direito à moradia adequada. (2014b). Belo Horizonte: Editora Fórum.

Sen, Amartya. (2010). Desenvolvimento como liberdade. Tradução de Laura Teixeira Motta. São Paulo: Companhia das Letras.

Silva, José Afonso da (2007a). Comentário contextual à Constituição. 4.ed. São Paulo: Malheiros.

Silva, José Afonso da (2007b). Direito Constitucional Positivo. 29.ed. São Paulo: Malheiros.

Souza, Sergio Iglesias Nunes de (2013). Direito à moradia e de habitação. 3.ed. São Paulo: Revista dos Tribunais.

Triola, Mário. F. (2014). Introdução à estatística: atualização da tecnologia. 11. ed. Rio de Janeiro: LTC, 2014.

Data de submissão: 30/09/2018

Data de aceite: 09/03/2020 